\author{
Nicola Latronico \\ Margaret S. Herridge
}

\section{Unraveling the myriad contributors to persistent diminished exercise capacity after critical illness}

Received: 1 July 2015

Accepted: 2 July 2015

Published online: 10 July 2015

(C) Springer-Verlag Berlin Heidelberg and ESICM 2015

N. Latronico $(\bowtie)$

Department of Medical and Surgical Specialties, Radiological Sciences and Public Health, University of Brescia, Brescia, Italy e-mail: nicola.latronico@unibs.it

\section{N. Latronico}

Department of Anesthesia, Critical Care and Emergency, Spedali Civili University Hospital, Brescia, Italy

\section{S. Herridge}

University Health Network and Toronto General Research Institute, Toronto, ON, Canada

\section{S. Herridge}

Interdepartmental Division of Critical Care, Institute of Medical Sciences, Toronto, ON, Canada

\section{S. Herridge}

Department of Medicine, University of Toronto, Toronto, ON, Canada

"Lack of activity destroys the good condition of every human being, while movement and methodical physical exercise save it and preserve it" (Plato).

In an article recently published in Intensive Care Medicine [1], Cerqueira Borges and colleagues report their results on measuring daily life physical activity levels, muscle strength, and exercise capacity in survivors of severe sepsis and septic shock. Measurements were taken on the ward for $12 \mathrm{~h}$ after ICU discharge and then again at 3 months after discharge at the patients' home and over a time period of 2 days using physical activity monitors worn by the patients. Various activities including sitting, lying, standing, walking, and changes in body position and energy expenditure were recorded. Values obtained during this 2-day period were compared with those of a control group of 50 healthy sedentary subjects. During hospitalization, patients spent $90 \%$ of their time lying in bed or sitting. Physical activity improved to 3 months but ICU patients achieved only $63 \%$ of the walking time compared to healthy sedentary subjects. Exercise capacity was evaluated using the 6-min walk distance (6MWD) test. Dominant upper (hand) and lower (quadriceps) limb muscle strength was quantified using a digital dynamometer, and inspiratory muscle strength was captured by measuring maximal inspiratory pressure. These data were compared with age- and sex-matched control reference data. Exercise capacity, limb and inspiratory muscle strength were reduced by half compared to predicted values and improved to $70 \%$ of predicted values by 3 months. Therefore, even several months after discharge from the hospital, the time spent in physical activities and measured muscle strength were considerably lower when compared to those of healthy people.

Similar data were obtained by Denehy and colleagues in a prospective cohort study of 49 critically ill patients with varied ICU admission diagnoses [2]. Twenty-four percent of patients had significant weakness during the ICU stay. At 2 months after discharge, participants wearing an accelerometer for a mean of $13 \mathrm{~h}$ per day for 7 days spent $90 \%$ of their time inactive and only $3 \%$ of their time was spent walking. The 6MWD was $64 \%$ of predicted normal values. Persistently diminished exercise capacity may be a robust theme across different disease states and not just affecting those patients after critical illness. In a series of COPD patients suffering acute exacerbations, patients had very low levels of physical activity during and after hospitalization captured by activity monitors [3]. The accuracy of these activity monitors in detecting the time spent in walking, different postures, counting steps, and estimating the energy 
expenditure is fairly good compared to video recording and indirect calorimetry. Perhaps an important 'next step' is to better understand how to capture this persistent reduction in exercise in a patient-centered manner. As one example, a PROactive consortium (http://www.proactive copd.com) is actively investigating "patient reported outcome (PRO) tools to investigate dimensions of physical activity that are judged as being essential by patients" [4].

What does this study tell us? First, the authors provide valuable, objective data to further support the persistence of physical limitation after critical illness months after the resolution of the aggressive and relentless muscle proteolysis documented in recent studies [5]; similar data have been reported in survivors of acute lung injury even 5 years after hospital discharge [6]. Second, they confirm that severe sepsis is an important cause of long-lasting physical dysfunction and muscle weakness after acute illness, as suggested by a recent official American Thoracic Society clinical practice guideline [7].

What does this study not tell us? It leaves unsettled why septic patients remain so inactive and for so long. Reasons for this may be several, as sepsis is associated with the development of several neurologic complications such as critical illness polyneuropathy and myopathy, and muscle deconditioning-all of which cause muscle weakness [8]. Sepsis is also frequently associated with acute encephalopathy, delirium, and mood disorders and each of these may also contribute to a decrease in mobility [8]. Delirium and weakness can interact with each other so that reduced mobility may be the culmination of concurrent physical and mental impairment [9]. Early exercise in the ICU is associated with reduced occurrence of delirium [10]. Benefits of exercise on brain health are well recognized, as regular physical activity decreases the risk of stroke, dementia, and depression in the general population. So perhaps we should encourage our patients surviving the extraordinary insult of critical illness to make a lifelong commitment to exercise, in exactly the same way that cardiologists do with patients after myocardial infarction. Whether exercise alone can restore this decline in functional capacity is unclear and individual factors that influence the severity of injury and the innate resilience of repair play a central role as well.

Sepsis is associated with increased mortality in the ICU and also for many years after hospital discharge [11]. The neurological sequelae of sepsis-ICU-acquired weakness (ICUAW) and delirium with cognitive impairment and mood disorders-may contribute to the excess long-term mortality that occurs after sepsis [11]. ICUAW has been associated with increased 1-year mortality [12]. Although outcome was influenced by myriad factors - and physical dysfunction is no exception (Fig. 1) - in the recent Prospective Urban Rural Epidemiology (PURE) longitudinal study [13], grip strength, as simple as it is, predicted all-cause mortality, cardiovascular and non-cardiovascular mortality, and occurrence of myocardial infarction and stroke across a broad range of countries and spectrum of income. So, skeletal muscle function is itself an important determinant of health and disease.

The study by Cerqueira Borges and colleagues reminds us that intensivists are no longer asked to simply save patients' lives. We are asked to minimize multisystem morbidity; to help patients recover and/or adapt to residual disability; and to assist families with new mood disorders and the emotional and physical burden of
Fig. 1 Contributors to the persistence of diminished exercise capacity after an episode of critical illness. Methodological aspects of outcome assessment include whether objective (i.e., manual muscle strength, 6-min walking distance) and/or subjective (i.e., health-related quality of life) measures of muscle strength and physical function are used, and the method (i.e., clinical visit or telephone interview) and timing of assessment

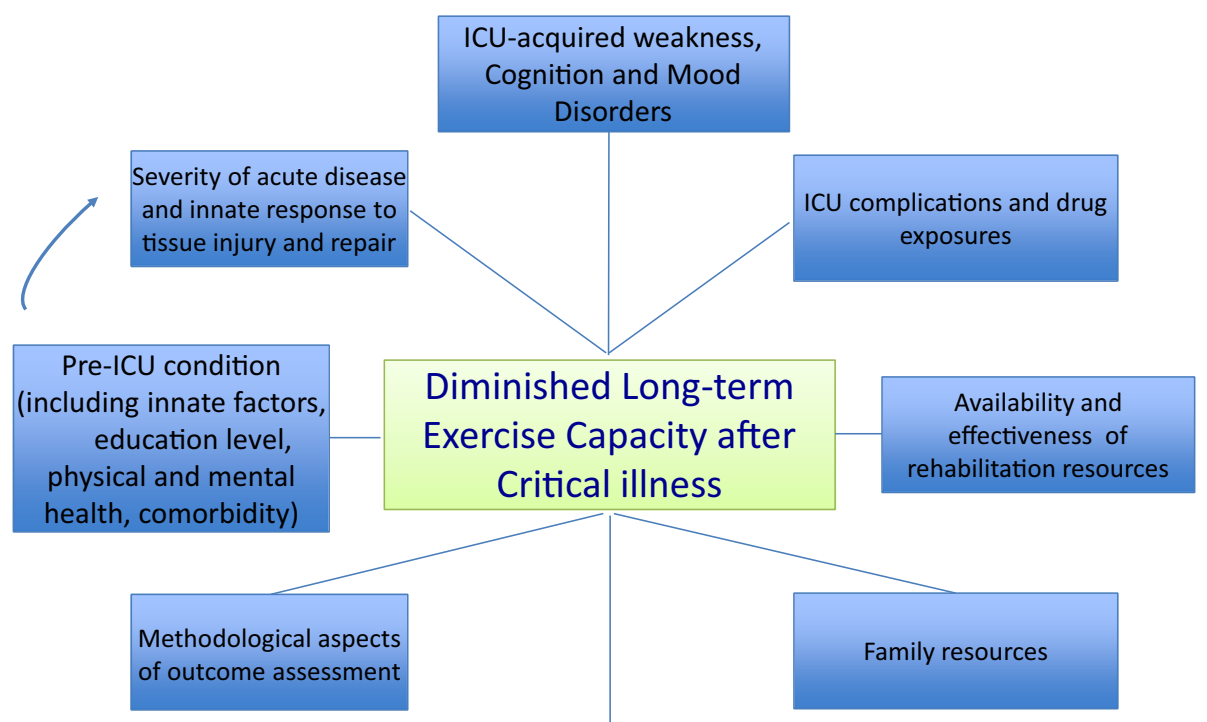

Social, political and economical landscape (including the health care system and gross domestic product) 
complex care delivery. Further, we need to lead and also embrace interprofessional and interdisciplinary collaboration to better understand and possibly modify the complexity of factors that initiate and then sustain physical and cognitive dysfunction, chronic pain disorders, sexual dysfunction, endocrinopathies, and the mental health challenges of anxiety, depression, and post- traumatic stress disorder [14]. We cannot do that alone. We need to work together and to stay at the forefront. Our patients "owe a debt to those outcomes-oriented intensivists who care about full recovery" [15].

Conflicts of interests On behalf of all authors, the corresponding author states that there is no conflict of interest.

\section{References}

1. Cerqueira Borges R, Carvalho CRF, Siqueira Colombo A, da Silva Borges MP, Soriano FG (2015) Physical activity, muscle strength, and exercise capacity 3 months after severe sepsis and septic shock. Intensive Care Med. doi:10.1007/s00134-015-3914-y

2. Denehy L, Berney S, Whitburn L, Edbrooke L (2012) Quantifying physical activity levels of survivors of intensive care: a prospective observational study. Phys Ther 92:1507-1517. doi: 10.2522/ptj.20110411

3. Van Remoortel H, Raste Y, Louvaris Z, Giavedoni S, Burtin C, Langer D, Wilson F, Rabinovich R, Vogiatzis I, Hopkinson NS, Troosters T, PROactive consortium (2012) Validity of six activity monitors in chronic obstructive pulmonary disease: a comparison with indirect calorimetry. PLoS One 7:e39198. doi: 10.1371/journal.pone.0039198

4. Pitta F, Troosters T, Probst VS, Spruit MA, Decramer M, Gosselink R (2006) Physical activity and hospitalization for exacerbation of COPD. Chest 129:536-544. doi: 10.1378/chest.129.3.536

5. Puthucheary ZA, Rawal J, McPhail M, Connolly B, Ratnayake G, Chan P, Hopkinson NS, Phadke R, Dew T, Sidhu PS, Velloso C, Seymour J, Agley CC, Selby A, Limb M, Edwards LM, Smith K, Rowlerson A, Rennie MJ, Moxham J, Harridge SD, Hart N, Montgomery HE (2013) Acute skeletal muscle wasting in critical illness. JAMA 310:1591-1600. doi: 10.1001/jama.2013.278481

6. Herridge MS, Tansey CM, Matté A, Tomlinson G, Diaz-Granados N, Cooper A, Guest CB, Mazer CD, Mehta S, Stewart TE, Kudlow P, Cook D, Slutsky AS, Cheung AM; Canadian Critical Care Trials Group (2011) Functional disability 5 years after acute respiratory distress syndrome. N Engl J Med 364:1293-1304. doi: 10.1056/NEJMoa1011802
7. Fan E, Cheek F, Chlan L, Gosselink R, Hart N, Herridge MS, Hopkins RO, Hough CL, Kress JP, Latronico N, Moss M, Needham DM, Rich MM, Stevens $\mathrm{RD}$, Wilson KC, Winkelman C, Zochodne DW, Ali NA; ATS Committee on ICU-acquired Weakness in Adults; American Thoracic Society (2014) An official American Thoracic Society clinical practice guideline: the diagnosis of intensive care unitacquired weakness in adults. Am J Respir Crit Care Med 190:1437-1446. doi:10.1164/rccm.201411-2011ST

8. Latronico N, Bolton CF (2011) Critical illness polyneuropathy and myopathy: a major cause of muscle weakness and paralysis. Lancet Neurol 10:931-941. doi:10.1016/S1474-4422(11)70178-8

9. Vasilevskis EE, Ely EW, Speroff T, Pun BT, Boehm L, Dittus RS (2010) ICUacquired delirium and weaknesscrossing the quality chasm. Chest 138:1224-1233. doi: 10.1378/chest.10-0466

10. Balas MC, Vasilevskis EE, Olsen KM, Schmid KK, Shostrom V, Cohen MZ, Peitz G, Gannon DE, Sisson J, Sullivan J, Stothert JC, Lazure J, Nuss SL, Jawa RS, Freihaut F, Ely EW, Burke WJ (2014) Effectiveness and safety of the awakening and breathing coordination, delirium monitoring/management, and early exercise/mobility bundle. Crit Care Med 42:1024-1036. doi: 10.1097/CCM.0000000000000129

11. Annane D, Sharshar T (2015) Cognitive decline after sepsis. Lancet Respir Med 3:61-69. doi: $10.1016 / \mathrm{S} 2213-2600(14) 70246-2$
12. Hermans G, Van Mechelen H, Clerckx B, Vanhullebusch T, Mesotten D, Wilmer A, Casaer MP, Meersseman P, Debaveye Y, Van Cromphaut S, Wouters PJ, Gosselink R, Van den Berghe G (2014) Acute outcomes and 1 -year mortality of intensive care unitacquired weakness. A cohort study and propensity-matched analysis. Am J Respir Crit Care Med 190:410-420. doi:10.1164/rccm.201312-2257OC

13. Leong DP, Teo KK, Rangarajan S, Lopez-Jaramillo P, Avezum A Jr, Orlandini A, Seron P, Ahmed SH, Rosengren A, Kelishadi R, Rahman O, Swaminathan S, Iqbal R, Gupta R, Lear SA, Oguz A, Yusoff K, Zatonska K, Chifamba J, Igumbor E, Mohan V, Anjana RM, Gu H, Li W, Yusuf S; Prospective Urban Rural Epidemiology (PURE) Study investigators (2015) Prognostic value of grip strength: findings from the Prospective Urban Rural Epidemiology (PURE) study. Lancet. doi: 10.1016/S0140-6736(14)62000-6

14. Stevens RD, Hart N, Herridge MS (eds) (2014) Textbook of post-ICU medicine: the legacy of critical care. Oxford University Press, Oxford

15. Misak CJ (2011) ICU-acquired weakness: obstacles and interventions for rehabilitation. Am J Respir Crit Care Med 183:845-846. doi: 10.1164/rccm.201007-1110OE 